\section{СОВРЕМЕННЫЕ ЭТНИЧЕСКИЕ ПРОЦЕССЫ У ТУВИНЦЕВ ЮГА КРАСНОЯРСКОГО КРАЯ}

\author{
Виктор П. Кривоногов \\ Сибирский федеральный университет
}

\section{CONTEMPORARY ETHNIC PROCESSES IN TUVAN POPULATION IN THE SOUTH OF KRASNOYARSKII KRAI}

\author{
Viktor P. Krivonogov \\ Siberian Federal University
}

В статье рассматриваются современные этнические процессы у группы тувинцев, издавна проживающей на территории России, в Красноярском крае, на границе с Тувой, по реке Ус, которых называют «усинскими тувинцами». С начала 1990-х годов, в связи с упадком животноводства и массовой безработицей, они почти все переселились в два русских села, составив в них меньшинство. С этого времени среди тувинцев, особенно в детских возрастных группах развернулись особые этнические процессы, которые была призвана исследовать этнографическая экспедиция с участием автора в 2014 г. Среди усинских тувинцев был проведен массовой опрос по этнографической анкете. Использованы были также методы бесед с информаторами и экспертами, изучены доступные статистические материаль. Проанализированы материалы похозяйственных книг из архива местного сельсовета на разные периоды.

Исследование выявило, что на русском языке вынуждены часто общаться даже те, для кого тувинский язык является родным. Наиболее ярко языковая ассимиляция проявляется в самой младшей возрастной группе. Все чаще детям даются русские имена. Все больше молодежи поет только на русском языке. В старшем поколении все знают несколько

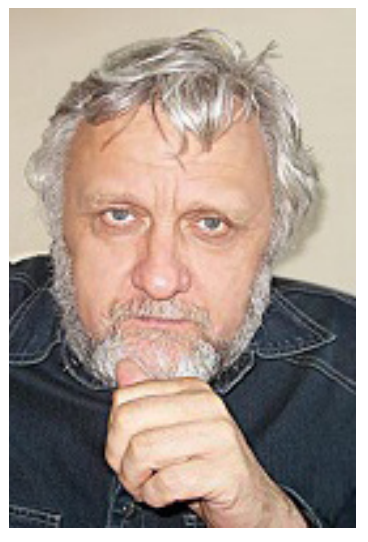

The article examines the contemporary ethnic trends in the group of Tuvans who for a long time have been residing in Krasnoyarskii Krai, near the border with the Republic of Tuva, along the river Us. They are habitually referred to as the 'Usinsk Tuvans'. Since early 1990s, due to the decay of cattle farming and mass unemployment, almost all of them have relocated to two Russian villages, where they now form a minority. After the move, the Tuvan population, especially its youngest age groups, have had specific ethnic experience which was investigated by an ethnographic expedition the author took part in in 2014. The Usinsk Tuvans were surveyed with the help of an ethnographic questionnaire. In addition, informant and expert discussions were held, and available statistical materials studied, as well as household books for a number of years from the local village council archive.

Our study has found that even those whose mother tongue is Tuvan commonly have to communicate in Russian. Linguistic assimilation was most

Кривоногов Виктор Павлович - доктор исторических наук, доцент, профессор кафедры всеобщей истории Гуманитарного института Сибирского федерального университета. Адрес: 660041, Россия, г. Красноярск, пр. Свободный, д. 79. Тел.: +7 (3912) 206-26-77, +7 (3912) 249-5935. Эл. адрес: victor950@yandex.ru

Krivonogov Viktor Pavlovich, Doctor of History, Associate Professor, Department of General History, Institute for the Humanities, Siberian Federal University. Postal address: 79 Svobodny Ave., 660041 Krasnoyarsk, Russian Federation. Tel.: +7 (3912) 206-26-77, +7 (3912) 249-59-35. E-mail: victor950@ yandex.ru 
народных сказок, а среди детей и подростков таких намного меньше

У населения присутствуют некоторые традиционные элементы в свадебном обряде, но более высокие показатели по соблюдению и знанию похоронного обряда. Встречается дуалистическая религиозная самоидентификация («буддизмшаманизм», «православие-буддизм», «православиешаманизм»), более трети усинских тувинцев считают себя неверующими.

Постоянно национальную одежду носят в основном женщины преклонного возраста. Большая часть усинских тувинцев (64,5\%) никогда не использует национальную одежду. Блюда национальной тувинской кухни встречаются в большинстве семей усинских тувинцев.

Смешанных семей оказалось по всем населенным пунктам 31,7\%, в межэтнические браки чаще вступают женщины. Значительное число смешанных браков ведет к появлению метисов.

Исследование позволило сформулировать ряд предположений о нарастающих ассимиляционных тенденциях в области языка и др. Все это ставит под вопрос существование данной группы в будущем. Несмотря на то, что почти половина усинских тувинцев полагают, что сохранятся как этническая группа, тем не менее вторая половина их или затрудняются прогнозировать, или допускают исчезновение их, полную ассимиляцию.

Ключевые слова: усинские тувинцы; Красноярский край; этнодемографические процессы; языковая ассимиляция; национально-смешанные семьи; духовная культура conspicuous in the youngest age group, where children are increasingly often given Russian names. Youth increasingly often sing only Russian song. While the elder generation still remembers several Tuvan fairy tales, there are fewer children and teenagers with such knowledge.

Tuvans still preserve only some elements of the traditional wedding rites, but funeral rites are better known and kept. Dualist religious self-identification can be observed (Buddhism-Shamanism, Orthodox Christianity - Buddhism, or Orthodox Christianity Shamanism). Over a third of Usinsk Tuvans identify as atheists.

Ethnic closing is habitually worn mainly by elderly women, while the majority of Usinsk Tuvans (64.5\%) never wear it. Dishes belonging to Tuvan national cuisine are cooked in most families.

31.7\% of households are mixed-marriage families, with women marrying a non-Tuvan more frequently than men. This significant proportion of mixed marriages means a higher percentage of mixedethnicity children.

Our study helped us arrive at a number of conclusions that linguistic and other forms of assimilation are on the rise. This casts doubt on the perspectives of the group's survival. Although almost half of Usinsk Tuvans believe they will survive as an ethnic group, the other half admit the possibility of full assimilation or are at a loss concerning their ethnic group's future.

Keywords: Usinsk Tuvans; Krasnoyarskii Krai; ethnodemographicprocesses; linguisticassimilation; mixed-marriage families; spiritual culture

\section{Введение}

Тувинцы, проживающие в России вне своей республики - в большинстве своем недавние мигранты, либо приехавшие туда временно - на учебу в разные вузы страны. Но есть одно место, где они отмечены давно, еще несколько веков назад, так что можно их назвать коренным народом России. Находится это место на границе с Тувой, в том месте, где проходил Усинский тракт - основной путь, связывающий Российскую империю с центральноазиатским регионом на юге Енисейской губернии.

В прошлые века границы государств не были такими охраняемыми как сейчас, и жившие по обе стороны границы люди могли более свободно общаться между собой. По нашу сторону границы располагались русские 
по составу населения села Верхнеусинское и Нижнеусинское, а кочующие южнее тувинцы-скотоводы, хотя и считались в то время «иностранными подданными», не очень считались с пограничным режимом, и часто кочевали по российскую сторону демаркационной линии. Судя по всему, несущие пограничную службу казаки смотрели на эти нарушения сквозь пальцы, и не чинили особых препятствий. Лишь изредка, когда отношения с южными соседями империи обострялись, казакам давался приказ выдворить «иностранцев», но как только отношения налаживались, кочевники возвращались на прежние кочевья, и какого-либо напряжения в отношениях это не вызывало.

Эта территориальная группа тувинцев получила названия по месту обитания (река Ус) «усинские тувинцы». Численность её в разные периоды постоянно менялась, так как существовала постоянная миграция через границу в обе стороны. Эта группа не привлекала в прошлом внимания исследователей и не становилась объектом изучения этнографов. Имеются лишь обрывочные данные о ее численности и расселении за различные периоды (Дацышен, 2009: Электр. ресурс; История Тувы, 2007: 49; Потапов, 1969). До вхождения Тувы в состав СССР тувинцы на данной территории официальной статистикой не учитывались, поскольку относились к иностранным гражданам, но позже, в 1950-е годы сведения о них появляются в учетных документах Верхнеусинского сельсовета (статью об истории усинских тувинцев В. Г. Дацышена см. также в этом же номере журнала. - ред.).

В 2013 г. на территории Верхнеусинского сельсовета силами магистрантов и сотрудников Гуманитарного института Сибирского федерального университета (Красноярск) была поведена этнографическая экспедиция, целью которой было выявление современных этнических процессов у местных тувинцев. Методами сбора информации был массовый опрос населения по этнографической анкете, а также беседы с информаторами и изучение статистических данных. Опросный лист состоял из 47 вопросов, касавшихся различных сфер жизни: материальной и духовной культуры, образования, занятости, языковых процессов и т. д. Всего было опрошено 279 респондентов, при этом данные о детях до 16 лет были получены со слов родителей. Была поставлена задача охвата опросом не менее $3 / 4$ тувинского населения, что удалось осуществить $(76,0 \%)$.

Некоторые результаты экспедиции уже были опубликованы в 20142015 гг. (Кривоногов, Михайлова, 2014; Krivonogov, Mikhailova, 2015; Михайлова, 2014: Электр. ресурс). 
В данной статье представлены основные результаты исследования, посвященного важнейшим современным этническим процессам усинских тувинцев.

\section{Общая характеристика усинских тувинцев}

Чтобы узнать ситуацию в расселении и численности тувинцев накануне нашей экспедиции, нами была произведена разработка похозяйственных книг местной сельской администрации. Оказалось, что в 1972 г. на территории сельсовета числилось 476 тувинцев, что составило 15,6\% ко всему местному населении, то есть, тувинцев был каждый шестой житель этой территории. Все русское население было сосредоточено в двух селах, а вот тувинцы, в большинстве своем, обитали вне сел, небольшими группами на многочисленных скотоводческих стоянках в радиусе 10-30 км от русских сел. Типичное поселение тувинцев в то время - это 2-4 дома близ кошары, коровника или иного животноводческого помещения. Из 476 тувинцев 368 чел. (77,3\%) проживало именно в таких поселениях, а в двух русских селах - 108 чел. (22,7\%), то есть, явное меньшинство. За 20-30 лет до этого в русских селах вообще тувинцев не было.

Раздельное с русскими проживание способствовало сохранению относительной эндогамии, а также тувинского языка в качестве основного разговорного и родного. Национально-смешанных семей в 1972 г. - всего 8 (8,7\% от числа всех тувинских семей), и все они проживали в русских поселках. В похозяйственных книгах 1950-х годов нам удалось обнаружить сведения всего о 2-х национально-смешанных семьях тувинцев. То есть, еще совсем недавно такие браки были большой редкостью. Около половины тувинского населения поселилось здесь уже после вхождения Тувы в состав России, примерно столько же считает, что их предки кочевали по Усу еще в 1930-е годы. Раздельное проживание русских и тувинцев позволяло последним в полном объеме сохранять родной язык, кроме того, существовали прочные связи с тувинцами, проживающими в соседних районах Тувы.

До вхождения в состав СССР местные тувинцы, считаясь иностранцами, все свои вопросы решали с администрацией смежных районов Тувы. Туда же отправлялись дети на учебу. После присоединения, они уже переориентировались на местные органы власти, были записаны в похозяйственные книги, и дети уже учились в местных школах, общим стало 
и хозяйство. Правда, за высшим и средним специальным образованием местная молодежь отправлялась чаще в Кызыл, и вообще местные тувинцы поддерживали тесные связи с соседями по ту сторону административной границы.

Коренной перелом в этнических процессах группы усинских тувинцев произошел в начале 1990-х годов. Связано это было с общеполитическими и экономическими процессами, происходящими в те годы во всей стране. Разрушение хозяйства привело к тому, что животноводство и скотоводство, которым в основном занимались тувинцы, полностью рухнуло, тувинцы лишились работы. В поисках выхода из этого кризиса, тувинцы покинули свои стоянки и почти в полном составе переехали в два русских поселка.

Ко времени нашей экспедиции из общей численности населения данной территории в 1990 человек - тувинцы составляли 367 чел. $(18,4 \%)$, из них 259 чел. поселились в Верхнеусинске, 99 - в Нижнеусинске, вне поселков осталось только 9 человек - на стоянке Усть-Теплая. За последние 20 лет сократилось и русское население, и тувинское, в основном в результате миграции населения по причине массовой безработицы.

В настоящее время в животноводстве занято всего 5,4\% тувинцев трудоспособного возраста, в других сферах деятельности 32,0\%, а большинство - 62,6\% оказались безработными. Высок уровень безработицы и среди местных русских. Многие местные жители, в том числе и тувинцы, пытаются выжить с помощью личного подсобного хозяйства, а также охоты и собирательства, которые также можно отнести к традиционным занятиям (Потапов, 1969). Практически у каждой семьи имеется приусадебный участок (огород), на котором выращиваются различные овощи и ягоды. Развитие огородничества, на наш взгляд, логично объяснить влиянием окружающего русского большинства.

Можно сказать, что и в хозяйстве, и в расселении усинских тувинцев за последние 20 лет произошли радикальные изменения. Сказалось все это и на этнических процессах, в частности, на языке.

\section{Языковые процессы}

Если до 1990-х годов тувинский язык у усинских тувинцев сохранялся довольно стойко, то у детей, родившихся после переселения в русские поселки, активно развернулся процесс языковой ассимиляции.

По всей группе тувинцев русскоязычными стало 17,2\%, еще 22,6\% считают родными оба языка, тувинский признали родным - 60,2\%. Но за 
этими общими показателями кроются огромные различия между разными возрастными группами. Среди стариков 100\% признали родным тувинский язык. Уже среди лиц среднего возраста (30-39 лет) 13,0\% стали русскоязычными, еще столько же признали родным оба языка, тувинский остался родным для 74,0\%. Совсем другая ситуация среди детей до 10 лет. Среди них (со слов родителей) родным является тувинский язык лишь для 28,3\%, еще для 30,3\% родными были оба языка, а для $41,4 \%$ - единственным родным оказался русский язык. То есть, среди детей русский язык распространен больше, чем тувинский. Несомненно, это стало следствием переезда в смешанную среду. Смешанная среда привела к тому, что на русском языке вынуждены часто общаться даже те, для кого тувинский язык является родным. Чаще разговаривает на тувинском языке лишь 14,4\% всех тувинцев всех возрастных групп, 35,1\% - чаще общается на русском, а остальные 50,5\% в равной степени используют оба языка.

Обратимся к показателям степени владения тувинским и русским языками. Всего тувинским языком свободно владеет $68,1 \%$ усинских тувинцев (табл. 1), при этом очень велики различия по возрастным группам. В группе старше 70 лет все свободно владеют тувинским языком, тогда как среди детей этот показатель опускается до 39\%, кроме того 45,9\% владеют тувинским языком частично или только понимают, а 14,5\% - не владеют вообще.

Таблица 1. Степень владения тувинским языком (опрос, в \%) Table 1. The degree of command of Tuvan language (survey data, \%)

\begin{tabular}{|c|c|c|c|c|}
\hline \multicolumn{5}{|c|}{ Степень владения тувинским языком } \\
\hline $\begin{array}{c}\text { Владеют } \\
\text { свободно }\end{array}$ & $\begin{array}{c}\text { С некоторыми } \\
\text { затруднениями }\end{array}$ & $\begin{array}{c}\text { Со значительными } \\
\text { затруднениями }\end{array}$ & $\begin{array}{c}\text { Понимают, но не } \\
\text { говорят }\end{array}$ & Не владеют \\
\hline 68,1 & 12,5 & 6,1 & 9,4 & 3,9 \\
\hline
\end{tabular}

Среди метисов уровень владения тувинским языком ниже, чем среди чистокровных тувинцев - $41,7 \%$ против $70,7 \%$.

Русским языком владеют свободно 90\% усинских тувинцев, остальные понимают, но испытывают затруднения в разговоре. Это в основном старики.

До недавнего времени тувинский язык изучался в местной школе, однако несколько лет назад количество желающих изучать резко упало, и этот предмет был исключен из программы. Однако до сих пор 75,8\% местных тувинцев (старше 7 лет) умеют и писать, и читать (еще 7,9\% - умеют только читать, а 16,3\% письменностью не владеют. Последние - в основном дети школьного 
возраста). Русской письменностью владеют практически все, за исключением нескольких стариков (97,9\% читают и пишут, 1,7\% только читают, 0,4\% - не владеют).

Приведенные данные по основным языкам региона позволяют сделать вывод, что с начала 1990-х годов, то есть сразу же после переселения тувинцев в поселки, начался процесс языковой ассимиляции, который наиболее ярко проявляется в самой младшей возрастной группе, то есть среди тех, кто родился уже в поселках. Ситуация в старших возрастных группах подтверждает вывод, что до переселения в поселки, ассимиляционные процессы в области языка практически отсутствовали.

\section{Имянаречение и фольклор}

В последние десятилетия детям усинских тувинцев все чаще стали давать русские имена. Сейчас тувинские имена и отчества имеют $13,4 \%$, русские имена и отчества - 42,2\%, остальные $44,4 \%$ - русские и тувинские имена и отчества в сочетании (т. е. русское имя - тувинское отчество. Или, реже - наоборот).

Самыми распространенными мужскими именами являются: Александр, Андрей, Николай, Дмитрий, Денис, Евгений и Максим (больше четырех носителей имени), в это же ряд попало одно традиционное тувинское имя Аяс (4 человека).

Самые распространенные женские имена: Марина, Вера, Людмила, Любовь, Елена, Валентина.

До недавнего времени тувинцы хорошо знали свои народные песни, но в связи с начавшейся языковой ассимиляцией появляется все больше молодежи, которая поет только на русском языке. Сейчас уже почти треть тувинцев национальных песен уже не знает (табл. 2).

Таблица 2. Знание усинскими тувинцами тувинских песен (опрос, в \%) Table 2. Knowledge of Tuvan song among the Usinsk Tuvans (survey data, \%)

\begin{tabular}{|c|c|c|}
\hline \multicolumn{3}{|c|}{ Знание тувинских песен } \\
\hline Не знают & Знают 1-3 песни & Знают более 3-х песен \\
\hline 32,8 & 24,5 & 42,7 \\
\hline
\end{tabular}

Лишь каждый седьмой респондент поет только по-тувински, остальные либо по-русски, либо на двух языках (табл. 3). 
Таблица 3. Язык исполнения песен усинскими тувинцами (опрос, в \%)

Table 3. Languages of songs sung by the Usinsk Tuvans (survey data, \%)

\begin{tabular}{|c|c|c|c|}
\hline \multicolumn{3}{|c|}{ Поют песни } \\
\hline На тувинском языке & $\begin{array}{c}\text { На русском и } \\
\text { тувинском языках }\end{array}$ & На русском языке & Не поют \\
\hline 14,7 & 49,5 & 31,9 & 3,9 \\
\hline
\end{tabular}

За общими показателями кроются большие различия в разных возрастных группах.

Все старики поют на тувинском, но при этом большинство из них могут петь и на русском языке. Большинство детей поют на русском, а вот на тувинском менее половины (43\%).

Молодежь, даже если поет по-тувински, предпочитает песни современные, эстрадные, старики предпочитают народные песни.

Знание усинскими тувинцами тувинских народных сказок показано в таблице 4.

Таблица 4. Знание тувинских сказок (опрос, в \%) Table 4. Knowledge of Tuvan fairy tales (survey data, \%)

\begin{tabular}{|c|c|c|c|}
\hline \multicolumn{4}{|c|}{ Народные сказки } \\
\hline Не слышали & $\begin{array}{c}\text { Слышали, но } \\
\text { рассказать не могут }\end{array}$ & Знают 1-3 сказки & $\begin{array}{c}\text { 3нают более 3 } \\
\text { Сказок }\end{array}$ \\
\hline 20,5 & 30,8 & 10,7 & 38,0 \\
\hline
\end{tabular}

В старшем поколении все знают более 3 народных сказок, а среди детей и подростков таких намного меньше - 14,3\%, хотя еще 57,1\% их слышали.

Таким образом, можно сделать вывод, что основными носителями фольклора является только старшее и среднее поколения.

\section{Обрядность, религиозная идентичность}

Обратимся к такому виду духовной культуры, как традиционные обряды, в частности свадебный и похоронный.

В республике многие тувинцы эти обряды в основном соблюдают (Юша, 2008). По словам наших информаторов, у усинских тувинцев также присутствуют некоторые традиционные элементы в свадебном обряде.

Согласно опросу, знают свадебный обряд или его отдельные элементы более половины опрошенных - 57,4\%. Этот обряд знают почти все старики, но только половина молодежи. 
Более высокие показатели у усинских тувинцев по соблюдению и знанию похоронного обряда - подавляющее большинство опрошенных $(89,4 \%)$ знают нормы или отдельные элементы этого обряда.

Исследователи отмечают, что к настоящему времени для погребального обряда тувинцев в республике характерны вынос покойного после полудня, наличие сопроводительного инвентаря, обильные поминальные подношения, отмечание поминальных дней на седьмые и сорок девятые сутки (Кисель, 2009). Все это присутствует у усинской территориальной группы тувинцев.

Информаторы и респонденты часто указывали на традицию разведения погребального костра на могиле усопшего. В Туве для проведения подобного обряда приглашается шаман и проводится он на третьи сутки (там же).

Учитывая происхождение значительной части жителей, Верхнеусинский Дом культуры (и его Нижнеусинский филиал) организует традиционные тувинские праздники, такие как Шагаа и Надым. Праздники имеют массовый характер и отмечаются всеми жителями сел независимо от их национальности. Опрос показал, что большинство усинских тувинцев отмечает праздники различного рода - и тувинские, и гражданские, и православные (таблица 5).

Таблица 5. Отмечаемые праздники (опрос, в \%)

Table 5. Festivals celebrated (survey data, \%)

\begin{tabular}{|c|c|c|}
\hline \multicolumn{3}{|c|}{ Отмечаемые праздники } \\
\hline Гражданские & Тувинские & Православные \\
\hline 97,5 & 85,0 & 75,0 \\
\hline
\end{tabular}

В опросе также выяснялась религиозная принадлежность взрослых респондентов. В результате получены следующие ответы: неверующие, буддисты, православные, шаманисты, несколько человек причислили себя к евангельским христианам.

Встречается дуалистическая религиозная самоидентификация: «буддизмшаманизм», «православие-буддизм», «православие-шаманизм», встретились и приверженцы сразу трех религий - «буддизм-православие-шаманизм» (табл. 6).

Таблица 6. Религиозная принадлежность усинских тувинцев (опрос, в \%) Table 6. Religious affiliation of the Usinsk Tuvans (survey data, \%)

\begin{tabular}{|c|c|c|c|c|c|c|c|c|}
\hline 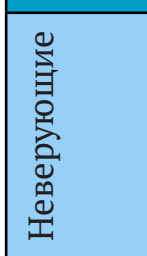 & 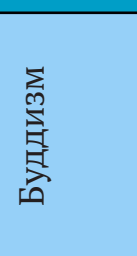 & 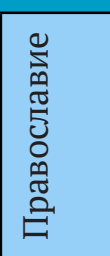 & 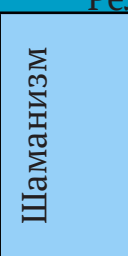 & 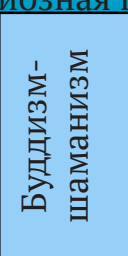 & 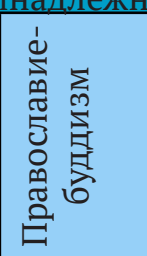 & 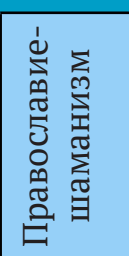 & 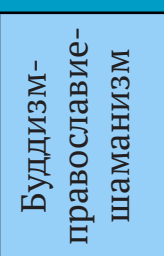 & 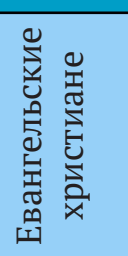 \\
\hline 35,9 & 25,5 & 9,4 & 4,2 & 14,1 & 1,5 & 1,5 & 4,1 & 3,8 \\
\hline
\end{tabular}


Более трети усинских тувинцев $(35,9 \%)$ считают себя неверующими. Четверть опрошенных отнесли себя к буддистам. Близкое соседство и интенсивные контакты с русскими привели к распространению среди части усинских тувинцев православия (16,5\%), правда, нередко в сочетании с другими религиями. $4,1 \%$ опрошенных признали себя приверженцами сразу трех религий «буддизмправославие-шаманизм».

Неверующих больше оказалось среди молодежи и пожилых людей. Больше всего приверженцев религиозного мировоззрения - в средних возрастных группах (30-50 лет). В этой возрастной категории больше и буддистов, и православных. Приверженцев шаманизма больше среди тех, кому за 50.

\section{Национальная одежда и питание}

Одной из сторон традиционной материальной культуры является наличие и использование национальной одежды.

Постоянно национальную одежду носят всего 4,3\% опрошенных (табл. 7), это в основном старики старше 70 лет (табл. 8), чаще - женщины (табл. 9).

Таблица 7. Использование национальной одежды (опрос, в \%) Table 7. Wearing ethnic clothing (survey data, \%)

\begin{tabular}{|c|c|c|}
\hline \multicolumn{3}{|c|}{ Использование национальной одежды } \\
\hline Носят постоянно & Иногда & Никогда \\
\hline 4,3 & 31,2 & 64,5 \\
\hline
\end{tabular}

Еще 31,2\% усинских тувинцев надевает национальную одежду изредка, лишь по праздникам, причем национальным. Большая часть усинских тувинцев $(64,5 \%)$ никогда не использует национальную одежду.

Таблица 8. Использование национальной одежды в разных возрастных группах (опрос, в \%)

Table 8. Wearing ethnic clothing in various age groups (survey data, \%)

\begin{tabular}{|l|l|l|l|l|l|l|l|l|}
\hline & \multicolumn{10}{|c|}{ До 10 } & $10-19$ & $20-29$ & $30-39$ & $40-49$ & $50-59$ & $60-69$ & 70 и старше \\
\hline $\begin{array}{l}\text { Носят } \\
\text { постоянно }\end{array}$ & 2,1 & & 2,1 & 2,2 & 6,8 & 4,7 & 11,1 & 50 \\
\hline Иногда & 45,8 & 30,1 & 26,5 & 32,6 & 25 & 42,9 & 11,1 & \\
\hline Никогда & 52,1 & 67,9 & 71,4 & 65,2 & 68,2 & 52,4 & 77,8 & 50 \\
& & & & & & & & \\
\hline
\end{tabular}


Таблица 9. Использование национальной одежды мужчинами и женщинами (опрос, в \%) Table 9. Wearing ethnic clothing in gender groups (survey data, \%)

\begin{tabular}{|l|c|c|}
\hline & Мужчины & Женщины \\
\hline Носят постоянно & 1,3 & 7,5 \\
\hline Иногда & 29,4 & 33,9 \\
\hline Никогда & 69,3 & 58,6 \\
\hline
\end{tabular}

В основном национальную тувинскую одежду покупают в Туве, часто ее привозят в подарок детям - этим и обусловлено довольно широкое использование национальной одежды в детской возрастной группе.

Блюда национальной тувинской кухни встречаются в большинстве семей усинских тувинцев. По сведениям информаторов, нередко готовят такие блюда как толган, быштак, хойтпак и др. Но чаще всего на столах усинских тувинцев появляется кровяная колбаса - хан. Согласно опросу, национальные блюда готовятся в $94 \%$ всех семей.

\section{Межэтническое взаимодействие}

Одной из форм межэтнического взаимодействия являются межэтнические браки. Как уже говорилось, в начале 1970-х годов, как нами подсчитано по похозяйственным книгам, смешанные семьи составили 8,7\%, причем в поселках, где жило меньшинство тувинцев - 27,6\%, а за пределами поселков, на стоянках - ни одной.

Сейчас, согласно нашей выборке, смешанных семей оказалось по всем населенным пунктам 31,7\%. Из числа смешанных семей две трети были семьи смешанные с русскими, треть - с другими национальностями (встретились единично браки с чувашами, хакасами, немцами, украинцами и т. д.). Лишь среди представителей старшего поколения (более 70 лет) межэтнические браки не зафиксированы, в остальных возрастных группах их насчитывается от 11 до 46\%.

В межэтнические браки чаще вступают женщины (табл. 10), в них состоит, согласно нашей выборке 30,1\% женщин-тувинок, но лишь 12,7\% мужчин.

Таблица 10. Доля состоящих в национально-смешанных браках (опрос, в \%) Table 10. Those in mixed marriages (survey data, \%)

\begin{tabular}{|l|c|c|}
\hline Национальность супруга & Мужчины & Женщины \\
\hline Тувинщы & 87,3 & 69,9 \\
\hline Русские & 8,5 & 20,7 \\
\hline Чуваши & & 3,7 \\
\hline Киргизы & & 1,9 \\
\hline Аварцы & & 1,9 \\
\hline Украинцы & & 1,9 \\
\hline Хакасы & 2,1 & \\
\hline Немцы & 2,1 & \\
\hline
\end{tabular}


Значительное число смешанных браков ведет к появлению метисов. Среди опрошенных их оказалось 10,7\% (табл.11).

Таблица 11. Этнический состав усинских тувинцев по данным генеалогий (опрос, в \%) Table 11. Ethnicity of the Usinsk Tuvans according to genealogies (survey data, \%)

\begin{tabular}{|c|c|c|c|c|c|}
\hline \multicolumn{7}{|c|}{$\begin{array}{c}\text { Этнический состав тувинцев } \\
\text { ные }\end{array}$} & $\begin{array}{c}\text { Тувинско- } \\
\text { русские } \\
\text { метисы }\end{array}$ & $\begin{array}{c}\text { Тувинско- } \\
\text { чувашские } \\
\text { метисы }\end{array}$ & $\begin{array}{c}\text { Тувинско- } \\
\text { хакасские } \\
\text { метисы }\end{array}$ & $\begin{array}{c}\text { Тувинско } \\
\text { - азербайд- } \\
\text { жанские метисы }\end{array}$ & $\begin{array}{c}\text { Тувинско- } \\
\text { якутские } \\
\text { метисы }\end{array}$ \\
\hline 89,3 & 8,7 & 1,1 & 0,3 & 0,3 & 0,3 \\
\hline
\end{tabular}

Метисов среди усинских тувинцев было бы намного больше, если бы они причисляли себя к данной национальности. Но оказалось, что намного чаще дети в смешанных семьях относятся родителями к национальности второго из супругов, поэтому они в число опрошенных не попали - влились в число русских. Такая ориентация метисов, наряду с миграцией молодежи в города, является одной из причин сокращения численности усинских тувинцев.

Большинство усинских тувинцев вполне терпимо относятся к разного рода контактам с окружающим русским большинством. Например, на вопрос об отношении к межэтническим бракам большинство ответили, что национальность супруга не имеет значения (56,8\%), еще $8,6 \%$ - даже предпочитают смешанные браки, и лишь 18,7\% ответили, что лучше браки «между своими» (остальные затруднились).

Так как русские на данной территории составляют большинство, то в первую очередь с ними усинские тувинцы вступают в контакты на различных уровнях: в работе, в быту и т. д. Именно поэтому при опросе был задан вопрос «Как Вы оцениваете свои взаимоотношения с русским населением?» Подавляющее большинство - 92,0\% ответили: «Нормальные».

Важным является мнение самих усинских тувинцев о будущем своей территориальной группы. Респондентам был задан вопрос «Как Вы думаете, сохранятся ли усинские тувинцы, со своими этническими особенностями в будущем?». Чуть меньше половины респондентов ответили, что усинские тувинцы сохранятся, меньший процент $(15,5 \%)$ считают, что их вскоре не станет (ассимилируются, разъедутся) и более трети не смогли ответить однозначно (табл. 12). 
Таблица 12. Мнение усинских тувинцев о перспективе сохранения своей территориальной группы в будущем (опрос, в \%)

Table 12. The opinions of the Usinsk Tuvans on the prospects of their ethnoterritorial group

(survey data, \%)

\begin{tabular}{|c|c|c|}
\hline \multicolumn{3}{|c|}{ Сохранятся ли усинские тувинцы в будущем? } \\
\hline Да & Нет & Затруднились в ответе \\
\hline 48,4 & 15,5 & 36,1 \\
\hline
\end{tabular}

\section{Заключение}

Подводя итоги, можно сказать, что до 1990-х годов рассматриваемая территориальная группа тувинцев - усинские тувинцы - неплохо сохраняла свои национальные особенности, язык, культуру. Но кризис хозяйства, приведший к массовому переезду их в русские поселки, положил начало активным ассимиляционным процессам, а также миграциям за пределы данной территории.

Исследование позволило сформулировать ряд предположений о нарастающих тенденциях. Например, очевидно, что ассимиляционные тенденции в области тувинского языка в ближайшие десятилетия будут нарастать. Преодоление языкового барьера привело к тому, что молодежь, желающая продолжить образование, уезжает не в Кызыл, как раньше, а в разные города России, в том числе и довольно далекие, вплоть до столицы.

Это и другие процессы ставят под вопрос существование этой группы в будущем. Несмотря на то, что почти половина усинских тувинцев полагают, что сохранятся как этническая группа, тем не менее вторая половина их или затрудняются прогнозировать, или допускают исчезновение их, полную ассимиляцию.

\section{СПИСОК ЛИТЕРАТУРЫ}

Дацышен, В. Г. (2009) Тувинское население Усинского пограничного округа Енисейской губернии. Из истории русско-тувинских отношений [Электронный ресурс] // Новые исследования Тувы. № 3. URL: https://nit.tuva.asia/nit/article/view/634 (дата обращения: 12.12.2016).

История Тувы (2007) / под общ. ред. В. А. Ламина. Новосибирск : Наука Т. 2. 430 с.

Кисель, В. А. (2009) Поездка за красной солью. Погребальные обряды Тувы. XVIII начало XXI в. СПб. : Наука. 111 с.

Потапов, Л. П. (1969) Очерки народного быта тувинцев. М. : Наука. 402 с.

Юша, Ж. М. (2008) Свадебная обрядность тувинцев: Традиции и инновации // Традиции и инновации в современном фольклоре народов Сибири / отв. ред. Г. Е. Солдатова. Новосибирск : Арта. 135 с. С. 52-62. 
Krivonogov, V. P., Mikhailova Ya. S. (2015) The Usinsk Tuvans in the XXI century // Жypнал Сибирского федерального университета. Серия «Гуманитарные науки». Т. 8, № 4, апрель. С. 793-804.

Кривоногов, В. П., Михайлова, Я. С. (2014) Современная этнография усинских тувинцев // Родина. № 7. С. 91-96.

Михайлова, Я. С. (2014) Современные языковые процессы у усинских тувинцев [Электронный ресурс] // Новые исследования Тувы. № 2. URL: https://nit.tuva.asia/nit/ article/view/164 (дата обращения: 13.12.2016).

Дата поступления: 15.12.2016 г.

\section{REFERENCES}

Datsyshen, V. G. (2009) The Tuvan population of Usinsk boundary district of the Yenisei province. From the history of relations between Russia and Tuva. The New Research of Tuva, no. 3 [online] Available at: https://nit.tuva.asia/nit/article/view/634 (access date 12.12.2016). (In Russ.).

Istoriia Tuvy (2007), ed. V. A. Lamin. Novosibirsk, Nauka Publ. Vol. 2.430 p. (In Russ.).

Kisel', V. A. (2009) Poezdka za krasnoi sol'iu. Pogrebal'nye obriady Tuvy. XVIII - nachalo XXI v. St. Petersburg, Nauka Publ. 111 p. (In Russ.).

Potapov, L. P. (1969) Ocherki narodnogo byta tuvintsev. Moscow, Nauka Publ. 402 p. (In Russ.).

Iusha, Zh. M. (2008) Svadebnaia obriadnost' tuvintsev: Traditsii i innovatsii. In: Traditsii $i$ innovatsii $v$ sovremennom fol'klore narodov Sibiri, ed. G. E. Soldatova. Novosibirsk, Arta. 135 p. Pp. 52-62. (In Russ.).

Krivonogov, V. P. and Mikhailova Ya. S. (2015) The Usinsk Tuvans in the XXI century. Zhurnal Sibirskogo federal'nogo universiteta. Seriia «Gumanitarnye nauki», vol. 8, no. 4, April, pp. 793-804. (In Russ.).

Krivonogov, V. P. and Mikhailova, Ia. S. (2014) Sovremennaia etnografiia usinskikh tuvintsev. Rodina, no. 7, pp. 91-96. (In Russ.).

Mikhailova, Ia. S. (2014) Sovremennye iazykovye protsessy u usinskikh tuvintsev. Novye issledovaniia Tuvy, no. 2 [online] Available at: https://nit.tuva.asia/nit/article/view/164 (access date: 13.12.2016). (In Russ.).

\section{Для цитирования:}

Submission date: 15.12.2016.

Кривоногов В. П. Современные этнические процессы у тувинцев юга Красноярского края [Электронный ресурс] // Новые исследования Тувы. 2017. № 1. URL: https://nit. tuva.asia/nit/article/view/695 (дата обращения: дд.мм.гг.). DOI: 10.25178/nit.2017.1.3

\section{For citation:}

Krivonogov V. P. Contemporary ethnic processes in Tuvan population in the south of Krasnoyarskii Krai. New Research of Tuva. 2007, no.1 [online] Available at: https://nit.tuva.asia/ nit/article/view/695 (access date: dd.mm.yy.). DOI: 10.25178/nit.2017.1.3 